\title{
Seasonal and local time variability of ripples from airglow imager observations in US and Japan
}

\author{
J. Yue ${ }^{1}$, T. Nakamura ${ }^{2}$, C.-Y. She ${ }^{3}$, M. Weber ${ }^{3}$, W. Lyons ${ }^{4}$, and T. Li $^{5}$ \\ ${ }^{1}$ High Altitude Observatory, National Center for Atmospheric Research, Boulder, CO, USA \\ ${ }^{2}$ National Institute of Polar Research, Tokyo, Japan \\ ${ }^{3}$ Department of Physics, Colorado State University, Fort Collins, CO, USA \\ ${ }^{4}$ FMA Research, Inc., Fort Collins, CO, USA \\ ${ }^{5}$ School of Earth and Space Sciences, University of Science and Technology of China, Hefei, Anhui, China
}

Received: 12 April 2010 - Revised: 8 June 2010 - Accepted: 29 June 2010 - Published: 2 July 2010

\begin{abstract}
Ripples as seen in airglow imagers are small wavy structures with short horizontal wavelengths $(<15 \mathrm{~km})$. Ripples are thought to form as the result of local instabilities, which are believed to occur when the amplitude of gravity waves becomes large enough. We have investigated ripple formation based on years of airglow imager observations located at Fort Collins, Colorado $\left(41^{\circ} \mathrm{N}, 105^{\circ} \mathrm{W}\right)$ and Misato Observatory, Japan $\left(34^{\circ} \mathrm{N}, 135^{\circ} \mathrm{E}\right) /$ Shigaraki MU Observatory $\left(35^{\circ} \mathrm{N}, 136^{\circ} \mathrm{E}\right)$. Na temperature-wind lidar observations are employed to detect convective and dynamic instabilities in the mesosphere and lower thermosphere (MLT) region over Fort Collins, Colorado. Seasonal variation of the ripple occurrence in Colorado is compared to that of the lidar-measured instability. The occurrence frequency of ripples varies semiannually, with maxima occurring during solstices and minima during equinoxes in both Colorado and Japan. However, the probability of convective and dynamic instabilities varies annually with a peak in Colorado winter. The seasonal variation of the occurrence frequency of ripples correlates with that of the gravity wave variances in the MLT. Ripple occurrence over Colorado also shows strong local time dependence, but it bears little resemblance to the local time dependence of instability probability.
\end{abstract}

Keywords. Atmospheric composition and structure (Airglow and aurora) - Meteorology and atmospheric dynamics (Middle atmosphere dynamics; Waves and tides)

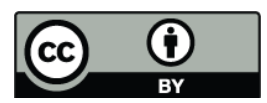

Correspondence to: $\mathrm{J}$. Yue (jyue@ucar.edu)

\section{Introduction}

Airglow emissions in the mesosphere and lower thermosphere (MLT) can be perturbed by atmospheric gravity waves (AGWs). Ground-based airglow imagers have been utilized to study these AGW activities by charactering the emission perturbation since Peterson and Kieffaber (1973). The most commonly observed feature is the quasi-monochromatic (QM) wave, which appears as coherent bands in the imagers (Peterson, 1979). QM waves have typical horizontal wavelengths of $20-30 \mathrm{~km}$ and periods of 5-20 min. Many of the QM waves are upward propagating AGWs from the lower atmosphere (e.g., Nakamura et al., 1998, 2003; Taylor et al., 1997), while some QM waves are ducted gravity waves travelling horizontally thousands of kilometers away from their sources (Walterscheid et al., 1999; Hecht et al., 2001).

In this paper, we present another wave phenomenon often observed in the airglow imager, known as ripples. Generally, localized structures with horizontal wavelength less than $15 \mathrm{~km}$ and periods less than the nominal Brunt-Vaisala period of 4-5 min are classified as ripples (Taylor et al., 1997; Nakamura et al., 1999). The review by Hecht (2004) shows that ripples are either Kelvin-Helmholtz (KH) billows induced by dynamic instabilities or convective billows induced by convective (static) instabilities. These scenarios are supported by concurrent airglow imager and lidar or radar MLT wind/temperature observations (Hecht et al., 2005, 2007; Li et al., 2005a, b). With the temperature and wind measured by lidar or radar, the squared Brunt-Vaisala (buoyancy) frequency $\left(N^{2}\right)$ and Richardson number $(R i)$ at the airglow layer can be derived and used as indexes for convective

Published by Copernicus Publications on behalf of the European Geosciences Union. 


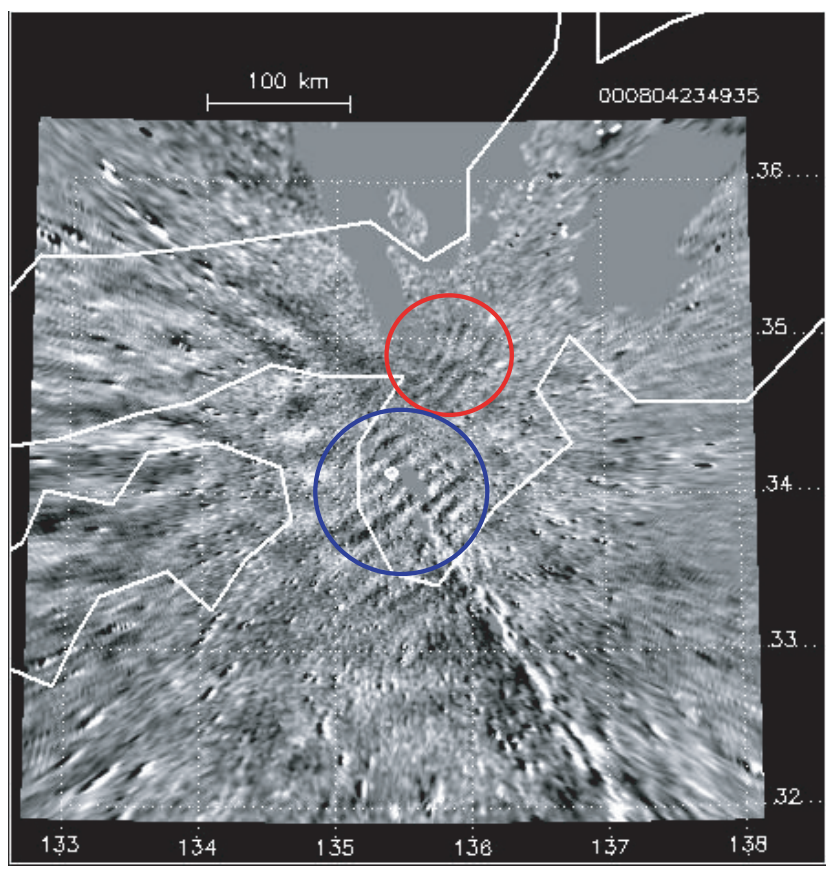

Fig. 1. Two ripples denoted inside the red and blue circle at the center of the $500 \times 500 \mathrm{~km}$ geographic map. The image was taken by the Misato imager at 23:49 UT on 4 August 2000. Longitudes and latitudes are marked on the side. The white curve is the Japanese coast line.

and dynamic stabilities (Fritts and Alexander, 2003; Hecht, 2004). The ripples in the airglow emission resulting from wave breaking can also be simulated in numerical models (Horinouchi et al., 2002; Horinouchi, 2004). Unlike previous case studies, we use 5 years of $\mathrm{OH}$ imager data in Colorado and 4 years of data in Japan to investigate the seasonal and local time variability of ripple occurrence. This is supplemented by the temperature/wind data from the Colorado State University (CSU) Na lidar, which provides the statistics of atmospheric instability at the $\mathrm{OH}$ airglow layer located at $\sim 87 \mathrm{~km}$. With this data, we can compare the ripple and instability statistics in Colorado.

\section{Instruments and data analysis}

One of the all-sky $\mathrm{OH}$ imagers was deployed at Yucca Ridge Field Station (YRFS) $\left(40.7^{\circ} \mathrm{N}, 105^{\circ} \mathrm{W}\right)$, Fort Collins, Colorado, in September 2003 (Nakamura et al., 2005). This imager is composed of a primary lens, an optical filter and a CCD camera. The CCD camera is a SBIG ST-1001E, binned to $512 \times 512$ pixels, and the CCD chip is only sensitive to wavelengths shorter than $1 \mu \mathrm{m}$. The primary lens is a Nikkor fish-eye lens ( $f=8 \mathrm{~mm}, \mathrm{f} / 2.8)$. The long-wave pass optical filter is a Kodak Wratten No. 87 with a cut-off wavelength of $795 \mathrm{~nm}$. This imager is designed to detect near-infrared (NIR) OH Meinel bands with an exposure time of $100 \mathrm{~s}$. One image is saved every $2 \mathrm{~min}$, and a dark image is obtained every $30 \mathrm{~min}$ with the shutter closed.

$\mathrm{OH}$ airglow images taken from a multicolor all-sky imager in Japan from 1999 to 2003 are included in this study (Fukushima, 2004). This imager was first installed at Shigaraki MU Observatory $\left(34.9^{\circ} \mathrm{N}, 136.1^{\circ} \mathrm{E}\right)$ in $1999 . \quad$ In 2000, the imager was moved to Misato Observatory $\left(34.1^{\circ} \mathrm{N}\right.$, $\left.135.4^{\circ} \mathrm{E}\right)$, Wakayama, Japan. There were no $\mathrm{OH}$ airglow observations in 2002. In this paper, we will call this the Misato imager for short. This imager uses a Nikkor fisheye lens $(f=6 \mathrm{~mm}, \mathrm{f} / 1.4)$ and a HAMAMATSU C4880-72S CCD camera. The $1 / 2$ inch-size CCD chip has $512 \times 512$ pixels. Interference filters are put in a rotating filter wheel to detect $\mathrm{OH}$ Meinel bands $(680-900 \mathrm{~nm})$, OI $(557.7 \mathrm{~nm}), \mathrm{Na}$ $(589 \mathrm{~nm})$, background $(572.3 \mathrm{~nm})$ and dark images, sequentially. The $\mathrm{OH}$ emission is detected every $5.5 \mathrm{~min}$ with an exposure time of $10 \mathrm{~s}$.

To process the raw airglow images, the first step is to rotate the images and place the North Star at the proper azimuth. Then corresponding dark images are subtracted from $\mathrm{OH}$ images to eliminate thermal noise. Since we are only interested in short-period ripples, every two successive 2-min-interval YRFS images are subtracted (Swenson and Mende, 1994; Li et al., 2005b; Yue et al., 2009). The resulting difference images have maximum response for a wave period of $4 \mathrm{~min}$, and the response declines as the wave period increases. Through this step, the background light and stars are effectively removed, while long period gravity waves are greatly attenuated. Because the typical ripple period is $2-4$ min characterized by a much faster $\mathrm{OH}$ imager (Hecht et al., 2007), the ripples are much more distinguished in the difference images than in the raw images. However, this difference method is less effective for the Misato imager. Since the Misato imager takes $\mathrm{OH}$ images $5.5 \mathrm{~min}$ apart, the corresponding difference image has peak sensitivity for a wave period of $11 \mathrm{~min}$, which is larger than the typical period of ripples. Due to this, the different frequency response between the YRFS and Misato imager could cause biases in the statistics of ripple occurrences. In the last step, we unwrap and project the difference images on to geographic maps of $500 \times 500 \mathrm{~km}$, assuming the nominal height of the OH layer is $87 \mathrm{~km}$ (Garcia et al., 1997; She and Lowe, 1998; Yue et al., 2009).

To ensure that the ripple statistics are correct, it is crucial to carefully distinguish ripples from upward propagating or ducted gravity waves (bands) and other small-scale waves. In the $\mathrm{OH}$ images, we first pick out wave features with horizontal wavelength smaller than $15 \mathrm{~km}$. Despite being commonly used, Nakamura et al. (1999) and Hecht (2004) have suggested that $15 \mathrm{~km}$ is an arbitrary boundary between ripples and bands. Some bands may have horizontal wavelengths less than $15 \mathrm{~km}$. Additional qualitative criteria are applied to pick ripples from small-scale features on a case-by-case basis. For example, ripples usually have shorter lifetime $(<45 \mathrm{~min})$ and cover a small geographic area $\left(<5 \times 10^{3} \mathrm{~km}^{2}\right)$. Compared to coherent band structures, ripple patterns look 

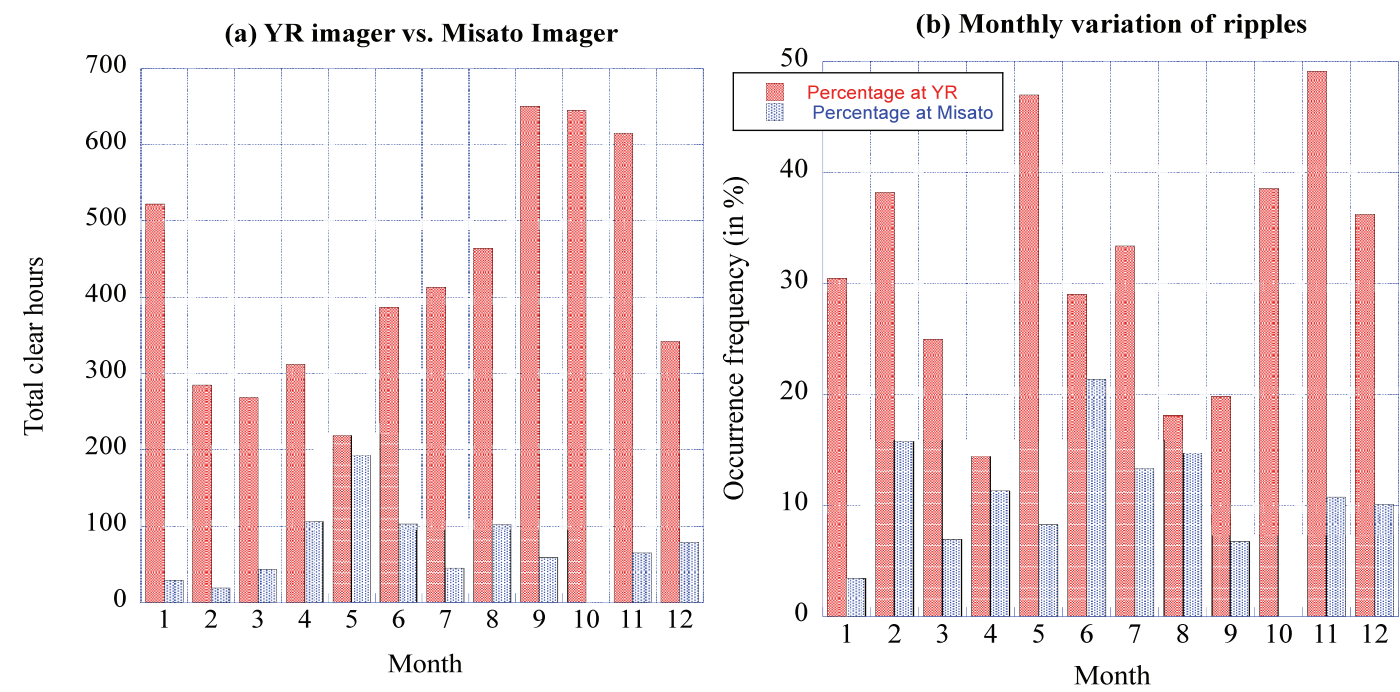

Fig. 2. (a) Monthly distribution of clear sky observation hours for the YRFS imager (red bar, 2003-2008) and the Misato imager (blue bar, 1999-2003). (b) Occurrence Frequency of ripples observed by each imager.

more broken and irregular. In many events, the phase front of a ripple is aligned at an angle to the associated AGW. Evanescent AGWs may also have small wavelengths. We know that evanescent AGWs have imaginary vertical wavelength. Without background temperature and wind information, the vertical wavelength cannot be evaluated. Therefore, we cannot rule out small-scale evanescent gravity waves from ripples. Fortunately, evanescent waves occur much less frequently than ripples (Hecht et al., 2007). So the inclusion of evanescent waves should not contaminate the ripple statistics. Figure 1 shows an example of ripples observed by the Misato imager on 4 August 2000. Two ripples with horizontal wavelength of $\sim 12$ and $15 \mathrm{~km}$ are denoted by two circles near the center of the map. Those two ripples are orientated in slightly different directions. Both lasted about $15 \mathrm{~min}$ ( 3 consecutive $\mathrm{OH}$ images).

The monthly distribution of clear sky observing hours at the YRFS and Misato Observatory is shown in Fig. 2a. The observing time for the YRFS OH imager (red bars) between 2003 and 2008 varies from $200 \mathrm{~h}$ to $600 \mathrm{~h}$ each month. Altogether there are $\sim 5000 \mathrm{~h}$ of clear sky observation from YRFS. The clear-sky observing time for the Misato imager (blue bars) from 1999 to 2003 is only $\sim 800 \mathrm{~h}$. Hardware breakdown of the Misato imager is partially responsible for this lack of data.

The Colorado State University (CSU) Na lidar is located $20 \mathrm{~km}$ southwest of the YRFS imager. This lidar system has been described by Arnold and She (2005). The narrowband Doppler lidar can simultaneously measure temperature $T$, zonal wind $U$ and meridional wind $V$ at $80-105 \mathrm{~km}$, weather permitting. From this information, the squared Brunt-Vaisala frequency $\left(N^{2}\right)$ and Richardson number $(R i)$ can be derived to estimate the convective and dynamic instabilities at the
$\mathrm{OH}$ airglow layer. $N^{2}$ is used to characterize the convective stability.

$N^{2}=\frac{g}{T}\left(\frac{d T}{d z}+\Gamma_{\mathrm{d}}\right)$

where $d T / d z$ is the vertical temperature gradient, $\Gamma_{\mathrm{d}}=$ $g / c_{p}$ is the dry adiabatic lapse rate $\left(\sim 9.5 \mathrm{~K} \mathrm{~km}^{-1}\right.$ in the mesopause region), $g$ is the gravitational acceleration $\left(\sim 9.5 \mathrm{~m} \mathrm{~s}^{-2}\right)$ and $c_{p}$ is the atmospheric specific heat at constant pressure (1004 $\left.\mathrm{J} \mathrm{K}^{-1} \mathrm{~kg}^{-1}\right)$. When $N^{2}$ is negative, i.e., when $-d T / d z$ is larger than the adiabatic lapse rate, the atmosphere can be convectively unstable. Dynamic instability characterized by $0<R i<0.25$ is caused by large wind shears and low static stability. The Richardson number is given by:

$R i=\frac{N^{2}}{(d U / d z)^{2}+(d V / d z)^{2}}=\frac{N^{2}}{S^{2}}$

where $S=\sqrt{(d U / d z)^{2}+(d V / d z)^{2}}$ is the total wind shear. Li et al. (2005b) and Nakamura et al. (2005) performed case studies on ripples over Colorado using this concurrent $\mathrm{OH}$ imager and CSU Na lidar data. In this work, we use the nocturnal temperature and wind lidar dataset between 2002 and 2005 to calculate the seasonal and local time variation of instability probability at the $\mathrm{OH}$ airglow layer. The temporal and vertical resolution of the lidar data is $15 \mathrm{~min}$ and $2 \mathrm{~km}$, respectively. The mean measurement uncertainty for the temperature and horizontal wind is $2 \mathrm{~K}$ and $3.5 \mathrm{~m} / \mathrm{s}$, respectively, around $87 \mathrm{~km}$ at the $\mathrm{OH}$ airglow layer. The averaged error for $N^{2}$ is $1.5 \times 10^{-4} \mathrm{~s}^{-2}$. 


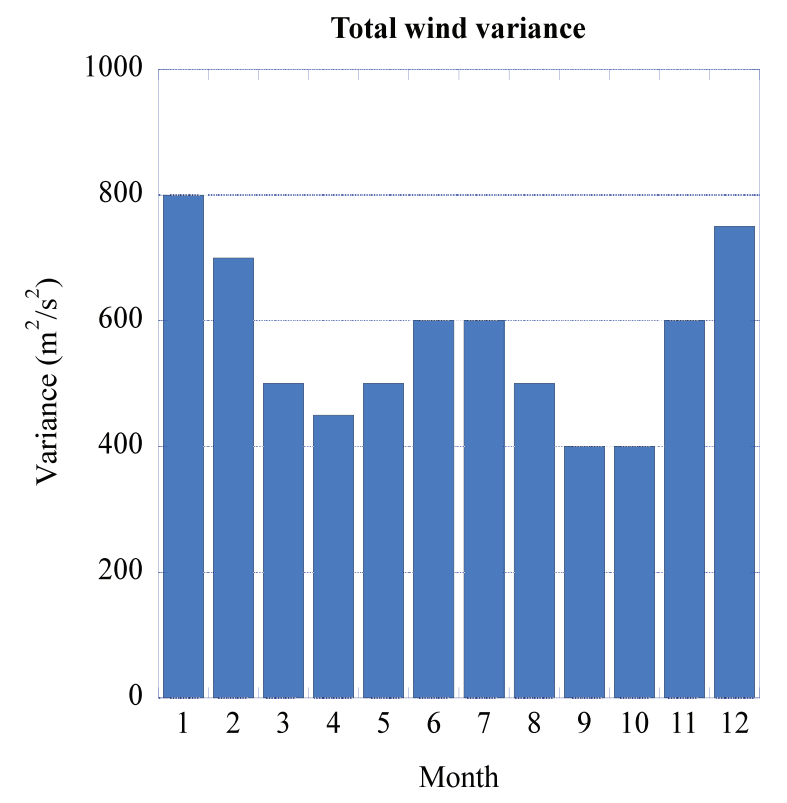

Fig. 3. Total wind variance at $87 \mathrm{~km}$ adopted from Fig. 4 of Gardner and Liu (2007).

\section{Results and discussion}

\subsection{Seasonal variability}

To calculate the occurrence frequency of ripples, airglow ripple images are identified within bins of $30 \mathrm{~min}$. Once ripples are identified within a certain 30-min bin, one ripple event is added to the sum of total ripple events. If two ripple events occur within one 30-min bin, this is still counted as only one event. However, this does not occur often. When no ripples can be found in a 30-min bin, this bin is tagged as having no ripple event. The occurrence frequency of ripples $p$ is calculated by dividing the number of half hours with ripples by the total number of half hours under clear sky condition, $n$. The confidence of the probability, or the error bar, is given by $\sqrt{\frac{p(1-p)}{n}}$.

Figure $2 b$ displays the histogram of the monthly mean occurrence frequency of ripples for the YRFS imager and Misato imager. The occurrence frequency of ripples is higher for the YRFS imager (red column) than the Misato imager (blue column). This is partially because the YRFS imager takes images every $2 \mathrm{~min}$, whereas the Misato imager takes images every $5.5 \mathrm{~min}$. This causes the YRFS difference images to be more sensitive to short period ripples than the Misato difference images. The geographical difference between the two sites may also contribute to the statistical difference. In order to obtain a more definitive conclusion, identical imager systems are needed.

Shown in Fig. 2b, ripples are more likely to occur near solstices over both Colorado and Japan. The occurrence frequency is the lowest during equinoxes. This is the same as previously published ripple climatology in Japan (Nakamura et al., 1999). We know that ripples form from instabilities when wave-induced temperature or wind gradient becomes large enough to perturb the mean state (Horinouchi et al., 2002; Horinouchi, 2004; Hecht, 2004). Sometimes AGWs with ripples may continue to break into turbulence (Yamada et al., 2001). As a consequence of AGW dissipation, the wave momentum flux is deposited into the mean state and the local eddy diffusion is enhanced. Indeed, the mesosphere eddy diffusion coefficient and momentum flux divergence show greater values during solstices than equinoxes (Fukao et al., 1994; Gardner and Liu, 2007). From observed seasonal dependent AGW activities, in particular the associated dissipations, one can deduce a seasonal distribution of the eddy diffusion coefficient. With a reasonable seasonal distribution of the eddy diffusion coefficient, models have revealed chemical composition (such as $[\mathrm{O}]$ and $\left[\mathrm{O}_{3}\right]$ ) dependence on eddy diffusion. Smaller diffusion results in higher concentration of species in the MLT (Garcia and Solomon, 1985; Qian et al., 2009). As they are correlated to the GW variances, the observed seasonal variation of ripple occurrence frequency in this work supports the eddy diffusion seasonality used in the models.

The seasonal variation of ripple occurrence frequency can be attributed to the seasonal change of AGW activities in the MLT region. Temperature and wind variances measured by the CSU Na lidar indicate higher wave activity during winter than during spring and fall equinoxes in Colorado (Fig. 5-11, Acott, 2009). This seasonal variation is in agreement with wind and temperature variances measured by radar and lidar at other locations (Nakamura et al., 1996; Gardner and Liu, 2007). We also see in Fig. $2 b$ that ripples occur more often in Colorado winter (November to February) than in summer (May to August), but ripples are observed more frequently in summer from the Misato images. This is in agreement with greater activity of AGWs in summer over Japan and in winter at higher latitude (Tsuda et al., 1990; Nakamura et al., 1996). Again, this suggests that AGW activities are statistically correlated with ripple occurrences. Since the CSU lidar thus far does not have enough measurements on short-period AGW variances during the summer season, we cannot use it for seasonal correlation studies with ripple occurrence. However, published AGW variances in Gardner and Liu (2009) cover all four seasons, and their lidar observations were made only hundreds of kilometers away from YRFS at Starfire Optical Range (SOR), New Mexico ( $35^{\circ} \mathrm{N}$, $106^{\circ} \mathrm{W}$ ). We could use their monthly mean total wind variances $U^{\prime 2}+V^{\prime 2}$ at $87 \mathrm{~km}$ for the correlation study. For this purpose, we read from the altitude-month contour plots of wind variances in Fig. 4 of Gardner and Liu (2007), and plot monthly mean AGW total wind variances at $87 \mathrm{~km}$ in Fig. 3 here. Compared to the occurrence frequency of ripples observed at YRFS in Fig. 2b, which has anomalously higher values in May and November, the seasonal variation in wave amplitude variances generally shows minima during 


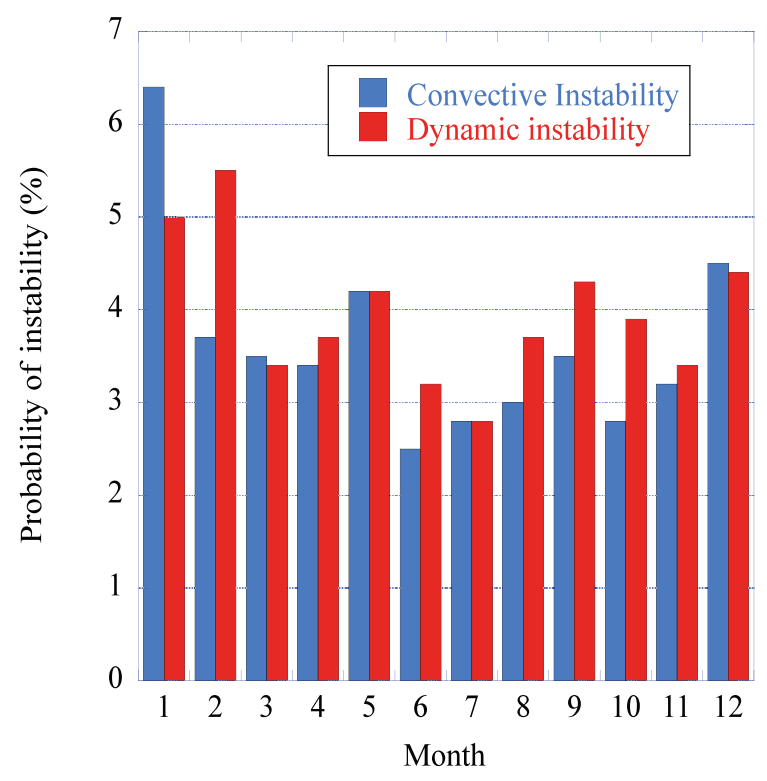

Fig. 4. Monthly mean probability of convective and dynamic instability at $83-91 \mathrm{~km}$.

equinoxes and maxima during solstices. Both the wind variance and ripple occurrence are slightly higher in winter than in summer. The correlation of the monthly wind variance and ripple occurrence is 0.32 throughout the year. If both ripple occurrence and wind variances are binned as seasonal averages (MA, MJJA, SO, NDJF binned respectively for spring, summer, fall, and winter), the correlation becomes 0.73 .

Figure 4 shows the probability of convective and dynamic instabilities measured by the CSU $\mathrm{Na}$ lidar at the $\mathrm{OH}$ layer $(87 \pm 4 \mathrm{~km})$, or between 83 and $91 \mathrm{~km}$. All available nocturnal lidar data between 2002 and 2005 are binned into cells of $2 \mathrm{~km}$ and $15 \mathrm{~min}$. The mean value of $N^{2}$ (or $R i$ ) and its associated standard deviations resulting from photon noise can then be calculated for each data point. Assuming the actual value is Gaussian distributed with a probability distribution function $P$ with the observed mean and photon noise standard deviation, the probability of convective instability for a data point in question can then be calculated from $P\left(N^{2}<0\right)$, or similarly for dynamic instability from $P(0<R i<0.25)$. The monthly mean probabilities of instability shown in Fig. 4 are the average value of all data points of the month between 83 and $91 \mathrm{~km}$. Figure 4 is consistent with the result of earlier instability studies in Colorado (Sherman and She, 2006). Because the lidar only monitors a small area of $100 \mathrm{~m}$ in diameter in the $\mathrm{OH}$ layer, and since the imager counts all ripples within the $500 \times 500 \mathrm{~km}$ field of view, the probabilities of instabilities are much smaller than the occurrence frequencies of ripples. Our results show that $P\left(N^{2}<0\right)$ has a maximum percentage of $6.4 \%$ in January and a minimum of $2.5 \%$ in June, and that $P(0<R i<0.25)$ has the maximum of $5.5 \%$ in February and the minimum of $2.7 \%$ in July. Instabil-
60

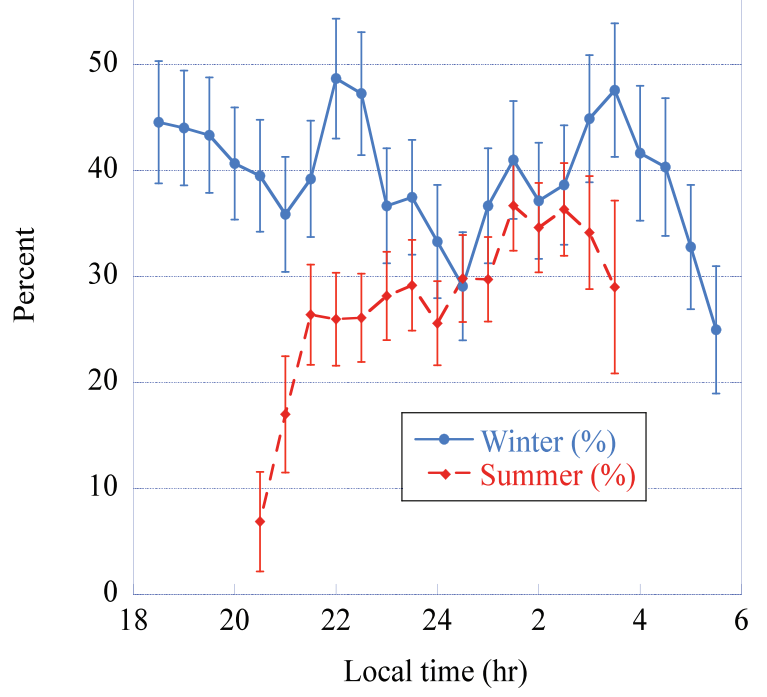

Fig. 5. Local time dependence of ripple occurrence frequency in Colorado. Error bar is denoted by the thin line. The summer here includes May, June, July and August; and winter includes November, December, January and February.

ity occurs more frequently in winter than in summer, while in Fig. 2b, the occurrence frequency of ripples is the lowest near spring and fall equinoxes. The seasonal variation of lidar-measured instabilities does not show clear correlation with that of the occurrence frequency of ripples, though it is commonly understood that ripples are originated from local instabilities.

There are several explanations behind this discrepancy. First of all, even using a much higher temporal and vertical resolution lidar ( $90 \mathrm{~s}$ a profile) and imager ( $3 \mathrm{~s}$ an image), Hecht et al. (2007) concluded that there was no one-to-one correspondence between ripples and lidar-measured unstable regions. The lidar-measured negative $N^{2}$ and small $R i$, which only implies that the atmosphere can potentially be unstable, but not necessarily that it will develop into ripples and turbulence. As suggested by Hecht (2004), the thickness of the unstable region is typically less than $2 \mathrm{~km}$. Limited by its time resolution ( $15 \mathrm{~min}$ ) and vertical resolution $(2 \mathrm{~km})$, the CSU Na lidar is not sensitive to short period instabilities with small vertical extent. Existing models and observational studies indicate that small-scale instabilities are more likely to generate ripples. However, since the local instability is a thin layer, it may not be observable by a ground-based imager unless its contrast in brightness is amplified by a sharp vertical gradient of the mixing ratio of atomic oxygen. This scenario often exists in the MLT (Ward, 1999, personal communication). 
(a) Summer

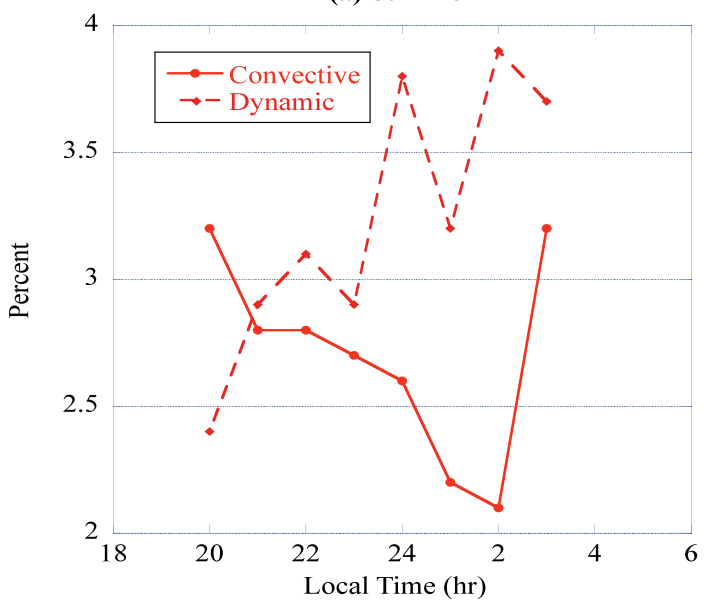

(b) Winter

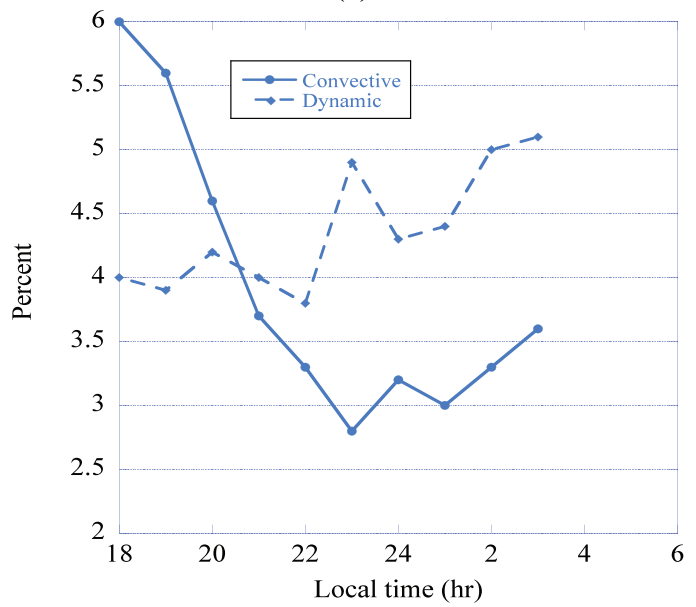

Fig. 6. The local time dependent probability of instabilities detected by the CSU Na lidar between 83 and $91 \mathrm{~km}$ in (a) summer and (b) winter.

\subsection{Local time variability}

The local time dependence of the occurrence frequency of ripples over Colorado is plotted in Fig. 5. The occurrence frequency of ripples for the Misato imager is not shown because of the sparseness in Misato data. In Fig. 5, winter data is shown with the blue line and summer with the red line. In winter, ripple occurrence has peaks of $48 \%$ around 22:00 and 04:00 local solar time (LST) and minima of 30\% around 00:00 and 06:00 LST. In summer, the chance to observe ripples increases from $7 \%$ at 20:00 LST to $35 \%$ at 02:00 LST. The ripple occurrence shows strong local time dependence. The probability of static and dynamic instability at the $\mathrm{OH}$ layer over Colorado is plotted in Fig. 6 as a function of local time. In summer, the convective instability decreases from $3.2 \%$ at 20:00 LST to $2.1 \%$ at 02:00 LST, and the probability of dynamic instability increases from $2.4 \%$ at 20:00 LST to $3.9 \%$ at $02: 00 \mathrm{LST}$. In winter, the probability of convective instability decreases from $6 \%$ at $18: 00 \mathrm{LST}$ to $2.8 \%$ at 23:00 LST, and the dynamic instability increases slowly from $4 \%$ at 18:00 LST to 5\% at 03:00 LST. The local time dependence of probability is quite different between convective and dynamic instabilities. Comparing Figs. 5 and 6, local-time occurrence frequency of ripples and probability of dynamic instability appear to be correlated. In winter, the peak of the probability of dynamic instability is about one hour behind the peak of the ripple occurrence. We do not see clear correlation between the occurrence frequency of ripples and convective instability. After sufficient CSU lidar data for shortperiod AGW variances in summer is obtained, the gravity wave variance as a function of local time will be investigated in future work to compare with the corresponding ripple occurrence.

\section{Conclusions}

In this work, we primarily show the seasonal and local time variability of occurrence frequency of ripples observed by $\mathrm{OH}$ airglow imagers at two midlatitude locations. At both sites, ripples are least likely to be observed near equinoxes. This is consistent with the seasonal variation of gravity wave activity, eddy diffusion and momentum flux divergence previously observed in the mesopause region. The CSU Na lidar measures more instability in winter than in summer at the airglow layer. We are unable to establish a strong statistical correlation between the seasonal variation of ripple occurrence and lidar-measured instability. On the other hand, with the observed AGW variances by the CSU lidar and the nearby SOR lidar, we find that wave variances are correlated with the occurrence frequency of ripples. The lack of correlation between the occurrence frequency of ripples and the probability of instability is partly attributed to the incapability of the CSU Na lidar to detect small-scale instabilities. These unstable regions of short vertical extent from the breaking of large-amplitude AGWs are responsible for most ripples. Furthermore, the large gradient induced by largeamplitude AGWs enhances the visibility of ripples. These are reasons why the gravity wave activity or variances are more correlated with the ripple occurrence rather than the lidar-measured instability. The ripple occurrence frequency in Colorado displays strong local time variability. Ripples most likely occur around 22:00 and 04:00 LST in winter and 02:00 LST in summer.

The vertical and temporal resolution of the Na lidar $(2 \mathrm{~km}$ and $15 \mathrm{~min}$ ) is apparently not high enough to detect all of small-scale instabilities with ripples. A temperature/wind $\mathrm{Na}$ lidar with higher resolution could mend this shortcoming. 
Acknowledgements. The work at Colorado State University; National Institute of Polar Research; and FMA Research is supported by grants from NSF, ATM-0545221; for Scientific Research (B) 14403008 and 20403011 from MEXT, Japan; and NSF, ATM0649034, respectively. The National Center for Atmospheric Research (NCAR) is sponsored by the National Science Foundation (NSF). The airglow observations at Misato and Shigaraki have been supported by Misato observatory and RISH, Kyoto University, respectively. JY's research is supported by the NCAR Advanced Study Program (ASP). The authors are grateful to Michael Hickey for valuable reviews and Jens Oberheide for providing SABER plots. JY thanks the helpful discussions with Deepak Simkahada and Qian Wu.

Topical Editor C. Jacobi thanks M. P. Hickey for his help in evaluating this paper.

\section{References}

Acott, P.: Mesospheric momentum flux studies over Fort Collins $\mathrm{CO}(41 \mathrm{~N}, 105 \mathrm{~W}), \mathrm{PhD}$ dissertation, Colorado State University, 2009.

Arnold, K. S. and She, C. Y.: Metal fluorescence lidar (light detection and ranging) and the middle atmosphere, Contemporary Physics, 44, 35-49, 2003.

Fritts, D. C. and Alexander, M. J.: Gravity wave dynamics and effects in the middle atmosphere, Rev. Geophys., 41(1), 1003, doi:10.1029/2001RG000106, 2003.

Fukao, S., Yamanaka, M. M. D., Ao, N., Hocking, W. K., Sato, T., Yamamoto, M., Nakamura, T., Tsuda, T., and Kato, S.: Seasonal variability of vertical eddy diffusivity in the middle atmosphere: 1. Three-year observations by the middle and upper atmosphere radar, J. Geophys. Res., 99, 18973-18987, 1994.

Fukushima, T.: A study on variability of airglow structure with dual-site imaging observations, Master thesis, Kyoto University, 2004.

Garcia, R. R. and Solomon, S.: The effect of breaking gravity waves on the dynamics and chemical composition of the mesosphere and lower thermosphere, J. Geophys. Res., 90(D2), 3850-3868, 1985.

Garcia, F. J., Taylor, M. J., and Kelley, M. C.: Two-dimensional spectral analysis of mesospheric airglow image data, Appl. Optics, 36(29), 7374-7385, 1997.

Gardner, C. S. and Liu, A. Z.: Seasonal variations of the vertical fluxes of heat and horizontal momentum in the mesopause region at Starfire Optical Range, New Mexico, J. Geophys. Res., 112, D09113, doi:10.1029/2005JD006179, 2007.

Hecht, J., Walterscheid, R., Fritts, D., Isler, J., Senft, D., Gardner, C., and Franke, S.: Wave breaking signatures in $\mathrm{OH}$ airglow and sodium densities and temperatures 1 . Airglow imaging, Na lidar, and MF radar observations, J. Geophys. Res., 102(D6), 66556668, 1997.

Hecht, J. H.: Instability layers and airglow imaging, Rev. Geophys., 42, RG1001, doi:10.1029/2003RG000131, 2004.

Hecht, J. H., Walterscheid, R. L., Hickey, M. P., and Franke, S. J.: Climatology and modeling of quasi-monochromatic atmospheric gravity waves observed over Urbana Illinois, J. Geophys. Res., 106, 5181-5195, 2001.

Hecht, J. H., Liu, A. Z., Walterscheid, R. L., and Rudy, R. J.: Maui Mesosphere and Lower Thermosphere (Maui MALT) observations of the evolution of Kelvin-Helmholtz billows formed near $86 \mathrm{~km}$ altitude, J. Geophys. Res., 110, D09S10, doi:10.1029/2003JD003908, 2005.

Hecht J. H., Liu, A. Z., Walterscheid, R. L., Franke, S. J., Rudy, R. J., Taylor, M. J., and Pautet, P.-D.: Characteristics of shortperiod wavelike features near $87 \mathrm{~km}$ altitude from airglow and lidar observations over Maui, J. Geophys. Res., 112, D16101, doi:10.1029/2006JD008148, 2007.

Horinouchi, T., Nakamura, T., and Kosaka, J.: Convectively generated mesoscale gravity waves simulated throughout the middle atmosphere, 29, 2007, doi:10.1029/2002GL016069, 2002.

Horinouchi, T.: Simulated breaking of convectively generated mesoscale gravity waves and airglow modulation, J. Atmos. Solar Terr. Phys., 66(6-9), 755-767, 2004.

Li, F., Liu, A. Z., Swenson, G. R., Hecht, J. H., and Robinson, W. A.: Observations of gravity wave breakdown into ripples associated with dynamical instabilities, J. Geophys. Res., 110, D09S11, doi:10.1029/2004JD004849, 2005a.

Li, T., She, C. Y., Williams, B. P., Yuan, T., Collins, R. L., Kieffaber, L. M., and Peterson, A. W.: Concurrent $\mathrm{OH}$ imager and sodium temperature/wind lidar observation of localized ripples over northern Colorado, J. Geophys. Res., 110, D13110, doi:10.1029/2004JD004885, 2005b.

Nakamura, T., Tsuda, T., Fukao, S., Manson, A., Meek, C., Vincent, R., and Reid, I.: Mesospheric gravity waves at Saskatoon $\left(52^{\circ} \mathrm{N}\right)$, Kyoto $\left(35^{\circ} \mathrm{N}\right)$, and Adelaide ( $\left.35^{\circ} \mathrm{S}\right)$, J. Geophys. Res., 101(D3), 7005-7012, 1996.

Nakamura, T., Tsuda, T., Miyagawa, H., Matsushita, Y., Fukunishi, H., Takahashi, Y., and Yamada, Y.: Propagation directions of gravity wave patterns observed in OH CCD images during the SEEK campaign, Geophys. Res. Lett., 25, 1793-1796, 1998.

Nakamura, T., Higashikawa, A., Tsuda, T., and Matsushida, V.: Seasonal variations of gravity wave structures in $\mathrm{OH}$ airglow with a CCD imager at Shigaraki, Earth Planets Space, 51, 897906, 1999.

Nakamura, T., Aono, T., Tsuda, T., Admiranto, A. G., Achmad, E., and Suratno: Mesospheric gravity waves over a tropical convective region observed by $\mathrm{OH}$ airglow imaging in Indonesia, Geophys. Res. Lett., 30(17), 1882, doi:10.1029/2003GL017619, 2003.

Nakamura, T., Fukushima, T., Tsuda, T., She, C. Y., Williams, B. P., Krueger, D., and Lyons, W.: Simultaneous observation of dual-site airglow imagers and a sodium temperature-wind lidar, and effect of atmospheric stability on the airglow structure, Adv. Space Res., 35, 1957-1963, 2005.

Peterson, A. W.: Airglow events visible to the naked eye, Appl. Optics, 18, 3390-3393, 1979.

Peterson, A. W. and Kieffaber, L. M.: Infrared photography of $\mathrm{OH}$ airglow structures, Nature, 242, 321-322, 1973.

Qian, L., Solomon, S. C., and Kane, T. J.: Seasonal variation of thermospheric density and composition, J. Geophys. Res., 114, A01312, doi:10.1029/2008JA013643, 2009.

She, C. Y. and Lowe, R. P.: Seasonal temperature variations in the mesopause region at mid-latitude: comparison of lidar and hydroxyl rotational temperatures using WINDII/UARD OH height profiles, J. Atmos. Solar-Terr. Phys., 60, 1573-1583, 1998.

Sherman, J. P. and She, C.-Y.: Seasonal variation of mesopause region wind shears, convective and dynamic instabilities above Fort Collins, CO: A statistical study, J. Atmos. Solar-Terr. Phys., 
68, 1061-1074, 2006.

Swenson, G. R. and Mende, S. B.: OH emissions and gravity waves (including a breaking wave) in all-sky imagery from Bear Lake, Utah, Geophys. Res. Lett., 21(20), 2239-2242, doi:10.1029/94GL02112, 1994.

Taylor, M. J., Pendleton Jr., W. R., Clark, S., Takahashi, H., Gobbi, D., and Goldberg, R. A.: Image measurements of short-period gravity waves at equatorial latitudes, J. Geophys. Res., 102, 26283-26299, 1997.

Tsuda, T., Murayama, Y., Yamamoto, M., Kato, S., and Fukao, S.: Seasonal variation of momentum flux in the mesosphere observed with the MU radar, Geophys. Res. Lett., 17(6), 725-728, 1990.
Walterscheid, R. L., Hecht, J. H., Vincent, R. A., Reid, I. M., Woithe, J., and Hickey, M. P.: Analysis and Interpretation of airglow and radar observations of quasi-monochromatic gravity waves in the upper mesosphere and lower thermosphere over Adelaide, Australia (35 S, 138 E), J. Atmos. Solar Terr. Phys., 61, 461-468, 1999.

Ward, W. E.: A simple model of diurnal variations in the mesopheric oxygen nightglow, Geophys. Res. Lett., 26(23), 35653568, 1999.

Yamada, Y., Fukunishi, H., Nakamura, T., and Tsuda, T.: Breaking of small-scale gravity wave and transition to turbulence observed in OH airglow, Geophys. Res. Lett., 28(11), 2153-2156, 2001.

Yue., J., Vadas, S. L., She, C. Y., Nakamura, T., et al.: Concentric gravity waves in the mesosphere generated by deep convective plumes in the lower atmosphere near Fort Collins, Colorado, J. Geophys. Res., 114, D06104, doi:10.1029/2008JD011244, 2009. 